\title{
In silico Identification of Resistance and Defense Related Genes for Bacterial Leaf Blight (BLB) in Rice
}

\author{
Ilakiya Sharanee Kumar, Nadiah Zaharin and Kalaivani Nadarajah* \\ Centre of Ecosystem Management and Natural Resources, Faculty of Science and Technology, Universiti \\ Kebangsaan 43600 UKM Bangi Malaysia.
}

\begin{abstract}
Bacterial leaf blight (BLB) disease is a rice disease caused by Xanthomonas oryzae pv.oryzae (Xoo). This disease causes devastating losses in the rice industry. To date research has been directed towards identifying QTLs and disease resistance genes that will afford resistance against $X o 0$. The rice plantations in different parts of the world are attacked by various strains of Xoo and thence the varieties that exhibit resistance to these strains may vary from one geographical location to another. In this paper we have analysed a QTL that has been recurrent in various rice backgrounds making it one of the three main QTLs responsible for BLB resistance in rice. qBBR11-1, a QTL found in chromosome eleven of rice is a good candidate for defense and resistance analysis towards BLB due to the various reports on the presence of multiple resistance genes in this QTL. Through the utilisation of bioinformatics tools we (1) identified and classified defense genes to functional groups, (2) identified and classified resistance genes according to the relevant domains, and finally, (3) mapped the relationship between defense related and resistance genes to build a defense model against BLB. A total of 21 defense genes have been classified according to functional groups such as chitinase activity, transduction signal and response to stress. A total of $\mathbf{3 7}$ putative resistance genes have been found and classified according to related domains such as nucleotide binding sites (NBS), trans membrane domains (Trd), WRKY domains and Ser / Thr Kin without LRR. Collectively all this information is used to provide a graphical representation of the interaction between the dense and the resistance gene systems. The key genes identified may be developed into markers for breeding or used in plant transformation works.
\end{abstract}

Keywords: Quantitative trait loci, bacterial leaf blight, resistance, dominant, defense, and pathways.

\footnotetext{
*Correspondence: vani@ukm.edu.my

(Received: 06 November 2018; accepted: 15 December 2018)
}

Citation: Ilakiya Sharanee Kumar, Nadiah Zaharin and Kalaivani Nadarajah, In silico Identification of Resistance and Defense Related Genes for Bacterial Leaf Blight (BLB) in Rice, J Pure App/ Microbiol., 2018; 12(4):1867-1876. http://dx.doi.org/10.22207/ JPAM.12.4.22

(C) The Author(s) 2018. Open Access. This article is distributed under the terms of the Creative Commons Attribution 4.0 International License which permits unrestricted use, sharing, distribution, and reproduction in any medium, provided you give appropriate credit to the original author(s) and the source, provide a link to the Creative Commons license, and indicate if changes were made. 


\section{INTRODUCTION}

Rice plants play an important role in generating income for more than 200,000 farming families in Malaysia ${ }^{1}$. However, paddy production in Malaysia is affected by a series of biotic and abiotic stresses that results in a reduction of yield. Disease has been a factor that results in all rice growing states. The production of new cultivars that have overall or partial resistance to disease, high yields and are able to survive in a nonconducive environment is of utmost importance. Since these pathogens are constantly evolving, the cultivars do not have a long self-life of remaining resistant to these pathogens. As such farmers have to resort to application of chemical controls as well as to adopt agricultural practices that reduce losses. However, prolonged use of chemical controls in circumventing disease is not advisable as the microbes in time become tolerant or resistant not to mention the deleterious effect on the environment and the handlers. Consequently, the production of rice varieties with high levels of resistance to disease is important and thus reducing dependence on chemical controls and pesticides ${ }^{1-3}$.

Plants have several defense mechanisms for biotic or abiotic stresses which may lead to death or inhibit growth. This mechanism is known as resistance. Every plant species is attacked by at least one hundred types of mycoplasmas, viruses, bacteria, fungi, nematodes, and insects. Therefore information and understanding of the host-pathogen interaction ${ }^{4}$ and the arsenals of gene interacting ${ }^{5}$ in the process of defense will make selection of good candidate cultivars easier for the breeders. This information will be used for the development of molecular markers that can be used in screening varieties for resistance to bacterial leaf blight ${ }^{1}$.

Xanthomonas oryzae pv. oryzae (Xoo), the causative agent of bacterial leaf blight (BLB) is currently becoming a huge problem in Malaysia, China and Taiwan where paddy fields are reporting large scale losses from this disease $2,3,6$. Furthermore, chemical control of this disease is ineffective in this monsoon climate region. The cultivation of resistant rice varieties has been proposed to be the most effective strategy to prevent BLB as this disease affects the quality of rice. Based on the study by Niño Liu et al. (2006), the production and breeding of resistant varieties that carry the resistance gene is the most effective and cost-effective approach to controlling the disease ${ }^{3}$. Many efforts have been directed to generate rice varieties that have high resistance to Xoo. Gen Xa4 provides high resistance to Xoo in various commercial rice varieties and has been widely used in rice programmes in Asia for more than a decade ${ }^{2}$. Extensive planting of long-term single-strain gene varieties carrying $X a 3$ gene in Japonica rice varieties and $\mathrm{Xa} 4$ gene in Indica rice varieties have demonstrated the discovery of virulent and dominant strains capable of overcoming disease resistance afforded by these genes ${ }^{6,7}$.

A total of 40 antimicrobial genes have been identified and most have been well-mapped and cloned ${ }^{8,9}$. According to Yasmin et al. (2017), a cross between Teqing and Lemont identified a QTL, qBBR11-1 which had exhibited two consecutive years of resistance to BLB disease caused by three types of Xoo; C2, C4, and C $5^{10}$. A study by Shanti et al. (2010) using the same rice varieties Teqing and Lemont show that qBBR11-1 has Xa4 which is the main gene against two types of Xoo; C2 and $\mathrm{C}^{11}$. Arunakumari et al. (2016), reported the presence of the $X a 21$ gene in crosses of Improved Samba Mahsuri (ISM) with MTU1010 12 . Among all the resistance genes that have been studied so far, the dominant gene $X a 21$ is derived from wild rice, Oryza longistaminata, which provides broad spectrum resistance against Xoo strains in India ${ }^{10}$. Wang et al. (2012), concluded in their report that qBBR11-1 is among the three QTLs that have resistance to $\mathrm{BLB}^{13}$. Gustave et al. (2011), in his work concerning crosses between IR4 and Azucena showed the presence of qBBR11-1 which is effective on all types of Xoo strains from Africa $^{14}$. This therefore indicates that this particular QTL is important for resistance to BLB.

In this study we conducted a systematic analysis of the genome sequence contained within this QTL. The genes were annotated and differentiated to resistance and defense related genes and these genes were then used to predict the interaction of these genes and how these genes collectively contribute to BLB resistance in rice. Key genes identified may be utilised in rice transformation, and marker development for rice improvement. All the above analysis will be 
conducted using the rice genome database and all available online bioinformatic tools. The details from this study and many similar QTL analysis will be utilised by our research group to develop an integrated map that may be utilised by breeders and scientists.

\section{METHODS}

The identification of the physical position of qBBR11-1

qBBR11-1 QTL position was determined using BLAST software (Basic Local Alignment Search Tool) from the National Center of Biotechnology server (NCBI) using flanking markers of qBBR111 i.e. ID111117 and RM6293. Left and right sequences of markers ID111117 and RM6293 were found from previous studies ${ }^{6}$. The range for left and right sequence for molecular markers ID111117 and RM6293 was displayed. Range is included in the search field on the Rice Genome Browser under MSU Rice Genome Annotation Project Database and Resource that provides information on annotated data for the genome of rice (rice.plantbiology.msu. edu/). This site provides sequence of genomes for the Nipponbare subspecies and has annotated sequence for 12 chromosomes of rice. This data is retrievable via the search page and Rice Genome Browser provides an integrated view for annotated data. The physical area of qBBR11-1 was displayed on the server. With that view, locus id located at the forefront and locus ID located at the back of qBBR11-1 is obtained. Then the cDNA sequence in FASTA-format for chromosome eleven was obtained from the Rice web site Genome Browser under the MSU-Rice Genome Annotation Project Database and all the sequence information between the markers were downloaded and stored in 'Text Document (*. txt') format.

\section{Bioinformatic analysis using Blast2GO}

The files with the FASTA sequences of qBBR11-1 was uploaded into Blast2GO (https:// www.blast2go.com/) for further analysis. BLAST obtained the descriptional annotations for a total of 214 genes in qBBR11-1 (Blast2GO > blast). We then proceeded with mapping and annotation that provided gene ontologies which allowed for the identification of genes that are reposible for function associated with defence and resistance (Blast2GO to mapping to annotation). A function known as enzyme coding was utilised to retrieve the enzyme annotation for the genes (Blast2GO to Analysis to Enzyme Code and KEGG to Run GO-EnzymeCode Mapping). This was followed by domain analysis conducted for each annotated gene to identify the presence of domains that are prevalent in R-genes (Blast2GO and Run InterProScan). Finally, a directed acyclic graph that explains the interconnecting pathways between the defence processes and resistance was mapped (Blast2GO to Graphs to Make GO Graph).

\section{RESULTS AND DISCUSSION \\ Overall gene distribution in qBBR11-1}

qBBR11-1 spans approximately 1.46Mbp region in chromosome 11 . Along this region, about 214 genes were localised with an average distribution of 147 genes per Mbp. The BLAST analysis via Blast2GO annotated 209 genes with description and the remaining 5 genes without any description. The data pertaining all the genes in qBBR11-1 is provided in supplementary table (Table S1:https://drive.google.com/open?id=1gpBEm8X zcawHvdU0jYQAvyy7aBuYkXbZ).

Based on this, it is observed that the copy number of transposable elements (TE) (53 genes) is much higher than other group of genes. Previous studies have confirmed the existence and abundance of transposable elements in plant genome ${ }^{13-14}$. While TE plays an important role in altering and shaping the plant genome, the exact mechanism behind the mode of action of TE genome plasticity and structure remains obscure. However, several studies revealed the possible conditions that may prompt TE insertion. A recent study suggested the alteration of genome expression by TE is in accordance with the imposition of stress on plants ${ }^{9}$. This suggests that the insertion of TE may drive the expansion of R-genes ${ }^{15,16}$.

Characterisation of R-genes and PRR in qBBR11-1

A total of $37(0.17 \%)$ R-genes and pattern recognition receptor (PRR) found in qBBR11-1 are listed in Table 1. R-genes are essential component of plant armoury against pathogen invasion. These R-genes are characterised by the presence of domains such as the well-known NBS-LRR, protein kinase and other domain arrangements, which have been used to classify resistance genes into eight different classes ${ }^{17}$. 
Table 1. List of R-genes in qBBR11-1 with respect to domains

\begin{tabular}{|c|c|c|c|}
\hline $\begin{array}{l}\text { Class of } \\
\text { R-genes }\end{array}$ & Description & Locus ID & Domain(s) \\
\hline \multirow[t]{21}{*}{ Class $1 / 2$} & $\begin{array}{l}\text { Disease resistance protein } \\
\text { RPM1-like }\end{array}$ & LOC_Os11g46070 & LRR \\
\hline & \multirow[t]{3}{*}{ Disease resistance protein RPP13 } & LOC_Os11g45790 & NBS \& LRR \\
\hline & & LOC_Os11g45930 & NBS \& LRR \\
\hline & & LOC_Os11g45980 & NBS \& LRR \\
\hline & Putative disease resistance & LOC_Os11g45750 & NBS \& LRR \\
\hline & \multirow[t]{6}{*}{ RPP13-like protein 2 isoform $\mathrm{X} 1$} & LOC_Os11g45780 & NBS \& LRR \\
\hline & & LOC_Os11g45820 & NBS \& LRR \\
\hline & & LOC_Os11g45840 & NBS \& LRR \\
\hline & & LOC_Os11g45850 & NBS \& LRR \\
\hline & & LOC_Os11g45924 & NBS \& LRR \\
\hline & & LOC_Os11g45970 & NBS \& LRR \\
\hline & Putative disease resistance & LOC_Os11g46210 & NBS \& LRR \\
\hline & \multirow[t]{3}{*}{ RPP13-like protein 3} & LOC_Os11g46130 & NBS \& LRR \\
\hline & & LOC_Os11g46140 & NBS \& LRR \\
\hline & & LOC_Os11g47447 & NBS \& LRR \\
\hline & \multirow{2}{*}{$\begin{array}{l}\text { Putative disease resistance } \\
\text { protein RGA3 }\end{array}$} & LOC_Os11g45600 & NBS \& LRR \\
\hline & & LOC_Os11g45620 & NBS \& LRR \\
\hline & \multirow{4}{*}{$\begin{array}{l}\text { NBS-LRR class disease } \\
\text { resistance protein }\end{array}$} & LOC_Os11g45990 & NBS \& LRR \\
\hline & & LOC_Os11g46050 & NBS \& LRR \\
\hline & & LOC_Os11g46080 & NBS \& LRR \\
\hline & & LOC_Os11g46200 & NBS \& LRR \\
\hline \multirow[t]{13}{*}{ Class 4} & Bacterial blight resistance & LOC_Os11g46970 & Protein kinase \& LRR \\
\hline & \multirow{3}{*}{ protein XA26 } & LOC_Os11g46980 & Protein kinase \& LRR \\
\hline & & LOC_Os11g47000 & Protein kinase \& LRR \\
\hline & & LOC_Os11g47170 & Protein kinase \& LRR \\
\hline & \multirow[t]{4}{*}{ Leucine Rich Repeat, putative } & LOC_Os11g46960 & Protein kinase \& LRR \\
\hline & & LOC_Os11g47160 & Protein kinase \& LRR \\
\hline & & LOC_Os11g47210 & Protein kinase \& LRR \\
\hline & & LOC_Os11g47180 & Protein kinase \& LRR \\
\hline & \multirow{5}{*}{$\begin{array}{l}\text { Probable LRR receptor-like } \\
\text { serine/threonine-protein } \\
\text { kinase At3g47570 }\end{array}$} & LOC_Os11g47030 & Protein kinase \& LRR \\
\hline & & LOC_Os11g47240 & Protein kinase \& LRR \\
\hline & & LOC_Os11g47290 & Protein kinase \& LRR \\
\hline & & LOC_Os11g47300 & Protein kinase \& LRR \\
\hline & & LOC_Os11g47310 & Protein kinase \& LRR \\
\hline \multirow[t]{9}{*}{ Class 8} & \multirow{7}{*}{$\begin{array}{l}\text { Major disease resistance } \\
\text { protein Xa4 }\end{array}$} & LOC_Os11g46810 & Protein kinase \\
\hline & & LOC_Os11g46860 & Protein kinase \\
\hline & & LOC_Os11g46880 & Protein kinase \\
\hline & & LOC_Os11g46950 & Protein kinase \\
\hline & & LOC_Os11g47140 & Protein kinase \\
\hline & & LOC_Os11g47150 & Protein kinase \\
\hline & & LOC_Os11g47110 & Protein kinase \\
\hline & $\begin{array}{l}\text { wall-associated receptor } \\
\text { kinase 3-like }\end{array}$ & LOC_Os11g46870 & Protein kinase \\
\hline & $\begin{array}{l}\text { wall-associated protein } \\
\text { kinase }\end{array}$ & LOC_Os11g46900 & Protein kinase \\
\hline
\end{tabular}

About 15 genes encoding disease resistance protein RPM1, RPP13 and RGA3 have NBS (nuclear binding site) and LRR (Leucine rich repeat) domains and fall into Class 1 or Class 2 R-genes. The presence of TIR/CC domain could not be traced using InterProScan hence these 
Table 2. List of defense-associated genes along with ID and functional groups

\begin{tabular}{lll}
\hline LOcus ID & \multicolumn{1}{c}{ Description } & Functional Group \\
\hline LOC_Os11g47500.1 & xylanase inhibitor protein 1-like & PR protein \\
LOC_Os11g47510.1 & xylanase inhibitor protein 1-like & PR protein \\
LOC_Os11g47580.1 & xylanase inhibitor protein 1-like & PR protein \\
LOC_Os11g47590.1 & xylanase inhibitor protein 1-like & PR protein \\
LOC_Os11g47600.1 & xylanase inhibitor protein 1-like & PR protein \\
LOC_Os11g47610.1 & xylanase inhibitor protein 1-like & PR protein \\
LOC_Os11g47520.1 & xylanase inhibitor protein 2-like & PR protein \\
LOC_Os11g47530.1 & xylanase inhibitor protein 2-like & PR protein \\
LOC_Os11g47550.1 & xylanase inhibitor protein 2-like & PR protein \\
LOC_Os11g47560.1 & xylanase inhibitor protein 2-like & PR protein \\
LOC_Os11g47570.1 & xylanase inhibitor protein 2-like & PR protein \\
LOC_Os11g47670.1 & osmotin-like protein & PR protein \\
LOC_Os11g47680.1 & osmotin-like protein & PR protein \\
LOC_Os11g46830.1 & hydroxyproline-rich & Cell wall fortifying \\
& glycoprotein-like & protein \\
LOC_Os11g45430.1 & E3 ubiquitin-protein ligase & Ubiquitin ligase \\
& RFWD3-like & \\
LOC_Os11g47700.1 & E3 ubiquitin-protein ligase EL5 & Ubiquitin ligase \\
LOC_Os11g45890.1 & subtilase-like protein & Subtilase-like protein \\
LOC_Os11g45740.1 & transcription factor MYB108 & Transcription factor \\
LOC_Os11g47460.2 & myb family transcription factor, & Transcription factor \\
& putative, expressed & \\
LOC_Os11g45920.1 & probable WRKY transcription & Transcription factor \\
& factor 41 & \\
LOC_Os11g47640.1 & probable monofunctional riboflavin & Riboflavin biosynthesis \\
& biosynthesis protein RIBA 3, & protein \\
\hline & chloroplastic isoform X2 & \\
\hline
\end{tabular}

genes could not be distinguished between class 1 and class 2 . These genes may be involved in elicitor triggered immunity (ETI) as 13 NBS/LRR domain containing genes related to bacterial blight resistance protein $X A 26$, probable LRR receptorlike serine/threonine-protein kinase At3g47570 and LRR were also found in this QTL These genes are from Class 4 R-genes as they constitute genes with protein kinase domains and LRR repeats. Xa26 is a R-gene that provides resistance against Xanthomonas oryzae and has LRR and receptorlike kinase protein. Five annotated genes fall into Class 4 R-gene and three genes in qBBR11-1-1were associated to wall-associated kinase (WAK). WAK belongs to receptor-like kinase (RLK), which plays a pivotal role in plant-triggered immunity (PTI) for pathogen recognition. RLK is a PRR, which is categorised under Class 8 R-gene. In addition, six genes annotated as major disease resistance protein $\mathrm{Xa4}$ were also included in this class.

Host plants defend themselves by several ways depending on the predator or pathogen. For microorganisms such as bacteria and fungus, host plant will first recognise the pathogen through a pathogen associated molecular pattern (PAMP), which is perceived by PRR such as RLK. Upon pathogen recognition, PTI will be activated to suppress pathogen infection. If PTI becomes unsuccessful, the pathogens will release their effectors to penetrate through the host plant. In this situation however the pathogen releases elicitors that will trigger ETI that is able to reduce the detrimental effect on the host. This arms race between the pathogen and host will continue as both coevolve in nature ${ }^{17}$. 


\section{Characterisation of defense-associated genes and regulatory genes in qBBR11-1}

To execute the downstream defense mechanism upon pathogen recognition, plant employs a myriad of defense-associated genes encoding pathogenesis-related proteins, enzymes, secondary metabolites, antimicrobial compounds, phytohormones and regulatory genes. As such, we are interested to investigate the genes responsible for defense against bacterial blight in qBBR11-1.
Based on the Blast2GO analysis, about 21 (0.1 $\%)$ genes are linked to processes and functions relevant to defense which is shown in Table 2 and Supplementary Table S1.

Eleven PR-8 protein related genes namely xylanase inhibitor 1 and 2 were arranged in tandem repeats in qBBR11-1. As the name suggests, xylanase inhibitor proteins are secreted by plants to inhibit the hydrolytic activity of fungal and bacterial enzymes like xylanase from

a)

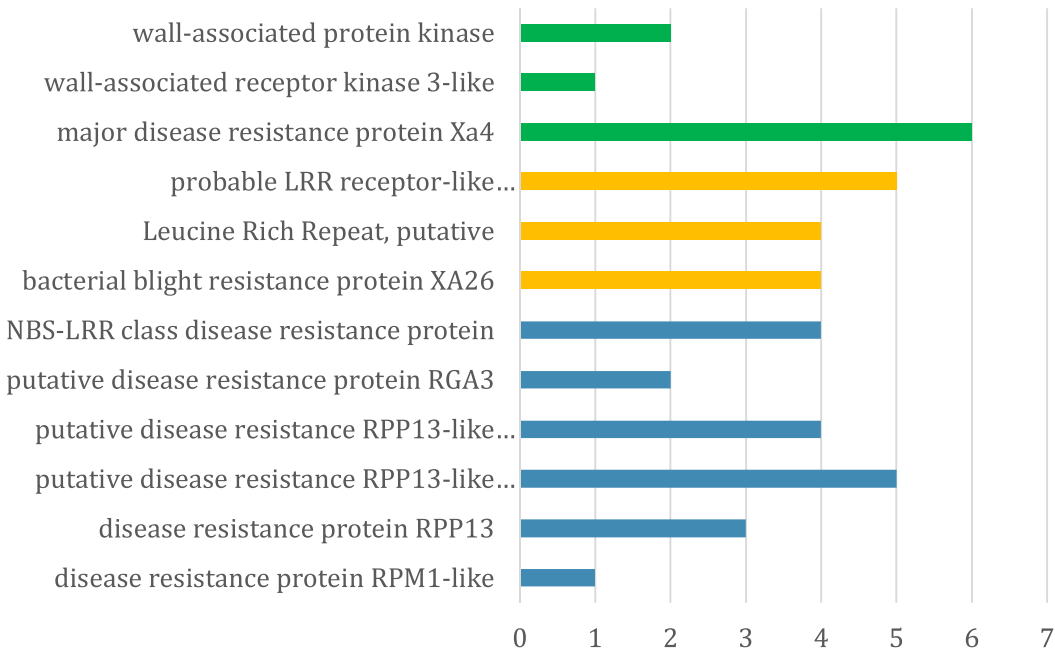

b)

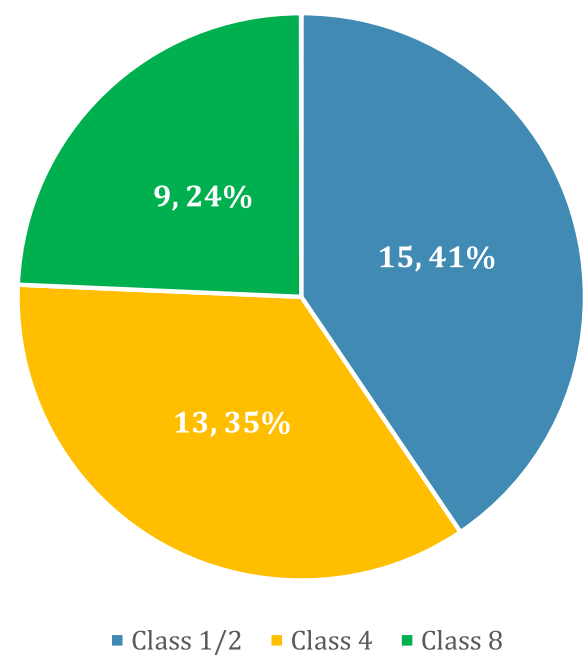

Fig. 1. The breakdown of R-genes in qBBR11-1 a) the number of -genes for each description b) the distribution of R-genes according to different R-genes classes 


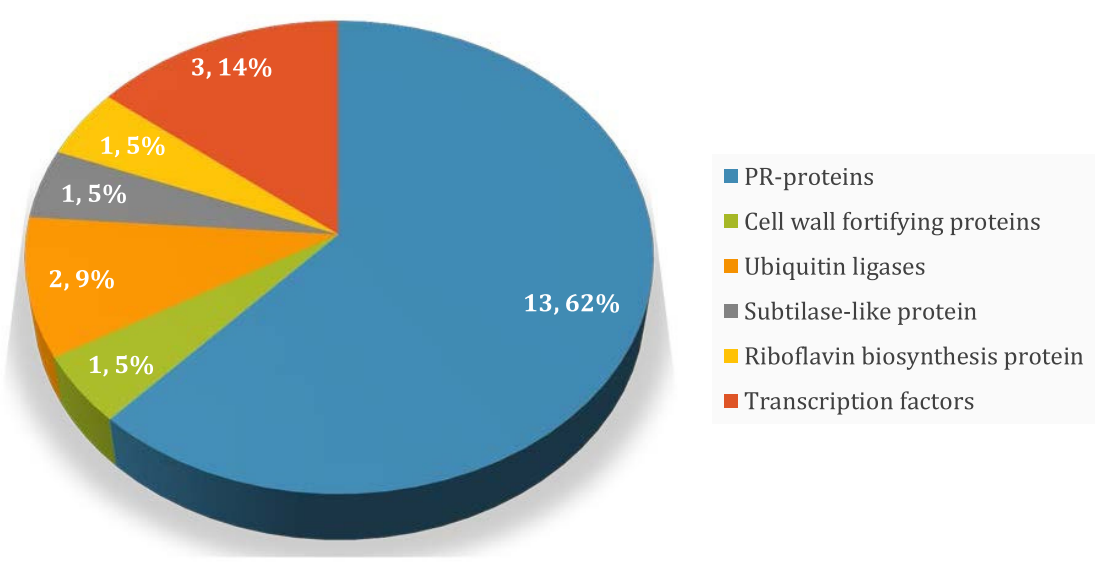

Fig. 2. Pie chart showing the breakdown of defense-associated genes according to respective functional group

degrading the plant cell wall ${ }^{18,19}$. A few studies reported that these group of proteins were induced by the signals related to plant stress imposed by pathogen ${ }^{20}$ and delays the disease symptoms ${ }^{21}$. Two genes found in qBBR11-1 are related to osmotin-like protein (OLP). OLP, from PR-5 protein family, plays a critical part in osmotic stress tolerance and defense against fungal and bacterial pathogens. The overexpression of OLP gene in transgenic sesame plants resulted in better tolerance against Macrophomina phaseolina which is mediated through SA and JA/ET signaling pathways $^{22}$.

Aside from that, a single gene encoding plant cell wall component known as hydroxyproline-rich glycoprotein-like (HRGP) is also observed in qBBR11-1. HRGP are involved in plant cell wall fortification ${ }^{23}$. In order to penetrate the rigid cell wall of plant cells, pathogens secrete hydrolytic enzymes such as pectinase, xylanase and polygalacturonases to degrade the polymers of cell wall $^{23}$. To further strengthen the plant cell wall, HRGP initiates the polymerisation of lignin and reorganises the cell wall architecture in response to pathogen attack ${ }^{24}$. Two genes encoding a regulatory enzyme known as E3 ubiquitin ligase were also found in qBBR11-1. The ubiquitination activity by E3 ubiquitin ligases is said to regulate the plant immune system ${ }^{25}$. In conjunction with that, these groups of enzymes were reported to modulate pathogen recognition by targeting PRR and R-genes. Specifically, in rice, the interaction of E3 ubiquitin ligase with receptor like kinase, a PRR, conferred resistance against bacterial blight ${ }^{19,21}$.

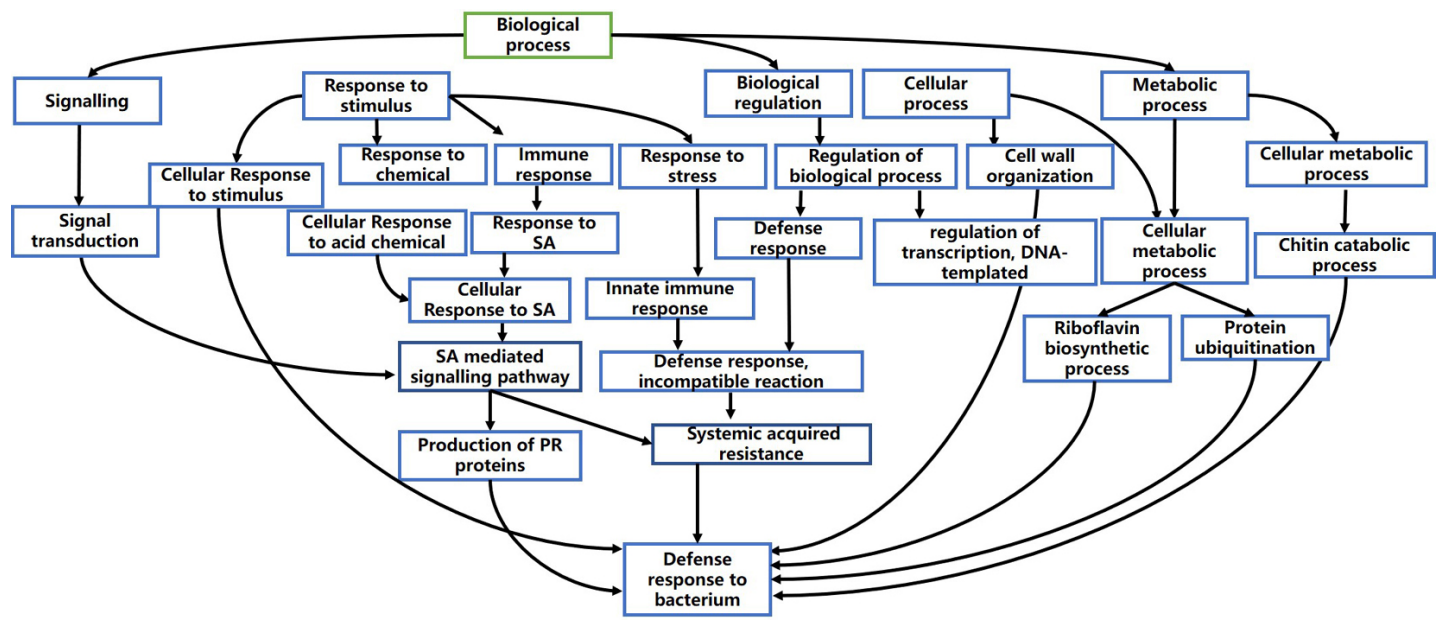

Fig. 3. Directed acyclic graph of defense mechanism in qBBR11-1 
In addition, subtilase-like protein, a proteolytic enzyme found in qBBR11-1, was proposed to play a role as membrane receptor to activate downstream signaling cascades pertaining defense against pathogens. Besides, Vartapetian et al. (2011) reviewed that they are involved in programmed cell death (PCD) that occurs as a consequence of hypersensitivity response ${ }^{27}$. PCD is manifested as necrotic flecks that restrict pathogens from spreading infections to other parts of the plants ${ }^{27}$. Three genes associated to Myb and WRKY transcription factors may be involved in the regulation of the defense response ${ }^{28-30}$. WRKY41, for example was implicated to be overexpressed in Arabidopsis thaliana upon recognising flagellin to enhance the resistance against Pseudomonas syringae which suggest the involvement of WRKY41 in ET1 ${ }^{22}$. Likewise, Myb108 has a similar function in $A$. thaliana ${ }^{30}$.

A gene related to riboflavin biosynthesis was also identified in this QTL which may be associated to plant defense. Riboflavin is generally regarded as vitamin B2 and is well known for its benefits in terms of nutritional value to humans. Interestingly, riboflavin is also required in plant defense response. In A. thaliana, PR genes are activated by riboflavin to induce systemic acquired resistance against the pathogen ${ }^{31}$.

To put it briefly, the signal from R-genes will be perceived and transmitted by subtilaselike protein followed by the accumulation of PR proteins at the site of infection which results in anti-bacterial activities that either inhibits the bacterial enzyme that degrades the host cell (PR-8) or directly involve in defense against bacterium The host cell wall will be further reinforced by HRGP to prevent the penetration of the pathogen into the cell machinery. On top of that, SAR will be activated following riboflavin biosynthesis. Towards the end of the defense process, transcription factors (WRKY and MYB) and regulatory enzyme such as E3 ubiquitin ligases will regulate the expression of defense-associated genes ${ }^{18-31}$.

Proposed mechanism for resistance against bacterial blight

As depicted in Figure 3, the plant defense system composed of several biological processes. Primarily the defense mechanism in qBBR11-1 will be established once PRR recognises the pathogen and sends the signal to downstream genes to execute PTI. However, if the pathogen is able to overcome this, the host plant will execute ETI with the aid of $R$-genes once it recognises the pathogen. R-genes will then send the signalling cascades to defense associated genes for downstream and specific defense responses.

One of the vital phytohormone required in plant stress signalling is salicylic acid (SA) which will be activated upon pathogen recognition. SA signalling molecules mediates the accumulation of PR proteins. Xylanase inhibitors 1 and 2, PR-8 proteins carry out chitin catabolic process to inhibit the xylanases produced by pathogen to degrade plant cell wall ${ }^{18-21}$. OLP, on the other hand is directly involved in defense response to bacterium ${ }^{22}$.

Riboflavin biosynthetic process supplements the SA signalling to the induce $S A R^{31}$. Besides, the signals from R-genes will also induce cell wall organisation by HRGP which adds mechanical barriers preventing the pathogen from entering the cell of the host plant ${ }^{23-24}$. Regulation of defense-associated genes remains as an integral part of defense. Protein ubiquitination by E3 ubiquitin ligase fine-rhythms the defenseassociated processes ${ }^{25,26}$. This is also accompanied by regulation of transcription by WRKY and MYB $\mathrm{TF}^{28-30}$.

\section{CONCLUSION}

Overall qBBR11-1 has a good combination of resistance and defense related genes that makes it a suitable target for use in breeding. In concordance with this, it is proposed that qBBR111 should be fine-mapped to eliminate genes that are not of interest to reduce unnecessary drag effect during breeding. A total of $37(0.17 \%)$ R-genes and PRR have been identified in qBBR111 . Out of these genes about $21(0.1 \%)$ are linked to processes and functions relevant to defense in rice. The eleven PR-8 protein related genes, namely xylanase inhibitor 1 and 2 in qBBR11-1 may be utilised in various molecular techniques such as cloning to develop resistant cultivar. The characterisation of the genes provided a rough outline of the resistance mechanism in this QTL which starts off with pathogen recognition by R-genes and subsequent signal transduction through several pathways such as SA and JA for the activation of downstream defense processes. It is therefore suggested that following fine mapping 
of this QTL, other relevant disease related QTLS should be identified and mapped to provide an integrated map that may be utilised by breeding programmes worldwide. Besides, this QTL can be used together with other well characterised QTLs such as qShb 9-2 ${ }^{32}$, qSBR11-133, qBFR4 and qLBL5 ${ }^{34}$ in breeding program that involve QTL pyramiding ${ }^{35}$ to develop varieties with multiple disease resistance.

\section{ACKNOWLEDGEMENTS}

The work presented here is funded by Universiti Kebangsaan Malaysia, DCP-2017-004/1.

\section{REFERENCES}

1. Abdullah FA and Samah BA. Factors impinging farmers' use of agriculture technology. Asian Social Science. 2013; 9 (3): 120.

2. Mew T. Current status and future prospects of research on bacterial blight of rice. Annual Review of Phytopathology 1987; 25 (1): 359382.

3. Nino Liu DO, Ronald PC, Bogdanove AJ. Xanthomonas oryzae pathovars: model pathogens of a model crop. Molecular Plant Pathology 2006; 7(5), 303-324.

4. Nadarajah, K., Ali, H. Z., and Mat Muni, N. The host pathogen interactions observed between Fusarium sp. F2 and Rice. Plant Omics Journal 2015; 8(6): 572-580.

5. Nadarajah K, Krishnan HK, Ali HZ. Cellular and molecular interactions of Magnaporthe oryzae S3 in rice. J Pure Appl Microbiol 2014; 8(5), 348191.

6. Tseng HY, Lin DG, Hsieh HY, Tseng YJ, Tseng WB, Chen CW, et al. Genetic analysis and molecular mapping of QTLs associated with resistance to bacterial blight in a rice mutant, SA0423. Euphytica 2015; 205 (1): 231-241.

7. Shi Z, Chen X, Line R, Leung $H$, Wellings C. Development of resistance gene analog polymorphism markers for the Yr9 gene resistance to wheat stripe rust. Genome, 2001; 44 (4): 509-516.

8. Kumar PN, Sujatha K, Laha G, Rao KS, Mishra $B$, Viraktamath $B$, et al. Identification and finemapping of Xa33, a novel gene for resistance to Xanthomonas oryzae pv. oryzae. Phytopathology 2012; 102 (2):222-228.

9. Sundaram RM, Chatterjee S, Oliva R, Laha GS, Cruz CV, Leach JE, et al. Update on bacterial blight of rice: fourth international conference on bacterial blight. Springer 2014.

10. Yasmin S, Hafeez FY, Mirza MS, et al. Biocontrol of Bacterial Leaf Blight of Rice and Profiling of Secondary Metabolites Produced by Rhizospheric Pseudomonas aeruginosa BRp3, Frontier in Microbiology. 2017; 8:1895. Published 2017 Sep 26. doi:10.3389/fmicb.2017.01895

11. Shanti ML, Shenoy VV, Lalitha Devi G, Mohan Kumar V, Premalatha P, Naveen Kumar G, Shashidhar HE, Zehr UB and Freeman WH. Marker-Assisted Breeding For Resistance To Bacterial Leaf Blight In Popular Cultivar And Parental Lines Of Hybrid Rice Journal of Plant Pathology. 2010; 92(2): 495-501

12. Arunakumari K, Durgarani C, Satturu V, Sarikonda $\mathrm{K}$, Chittoor P, Vutukuri B, et al. Marker-assisted pyramiding of genes conferring resistance against bacterial blight and blast diseases into Indian rice variety MTU1010. Rice Science, 2016; 23 (6):306-316.

13. Wang X, Chen J, Yang Y, Zhou J, Qiu Y, Yu C, Cheng $Y$, Yan, C, Chen J. Characterization of a Novel NBSLRR Gene Involved in Bacterial Blight Resistance in Rice. Plant Molecular Biology Reporter. 2012; 31. 10.1007/s11105-012-0537-0.

14. Gustave D, Marie-Noëlle N, Thierry M, Casiana C, Ambaliou S, Alain G \& Valerie V. Evaluation of African Cultivated Rice Oryza glaberrima for Resistance to Bacterial Blight. Plant Disease. 2011; 95. 441-447. 10.1094/PDIS-08-10-0558.

15. Bennetzen JL. Transposable element contributions to plant gene and genome evolution. Plant Molecular Biology, 2000; 42 (1): 251-269.

16. Makarevitch I, Waters AJ, West PT, Stitzer M, Hirsch CN, Ross-lbarra J, et al. Transposable elements contribute to activation of maize genes in response to abiotic stress. PLOS Genetics, 2015; 11 (1):e1004915.

17. Gururani MA, Venkatesh J, Upadhyaya CP, Nookaraju A, Pandey SK, Park SW. Plant disease resistance genes: current status and future directions. Physiological and Molecular Plant Pathology, 2012; 78: 51-65.

18. Gebruers K, Debyser W, Goesaert H, Proost P, Van Damme J, Delcour JA. Triticum aestivum L. endoxylanase inhibitor (TAXI) consists of two inhibitors, TAXI I and TAXI II, with different specificities. Biochemical Journal, 2001; 353 (2):239-244.

19. Gusakov A. Proteinaceous inhibitors of microbial xylanases. Biochemistry (Moscow), 2010; 75 (10): 1185-99.

20. Igawa T, Tokai T, Kudo T, Yamaguchi I, Kimura MA. wheat xylanase inhibitor gene, Xip-I, but not Taxi-I, is significantly induced by biotic and abiotic signals that trigger plant defense. 
Bioscience, Biotechnology, And Biochemistry, 2005; 69 (5):1058-1063.

21. Moscetti I, Tundo S, Janni M, Sella L, Gazzetti K, Tauzin A, et al. Constitutive expression of the xylanase inhibitor TAXI-III delays Fusarium head blight symptoms in durum wheat transgenic plants. Molecular Plant-Microbe Interactions, 2013; 26 (12):1464-1472.

22. Chowdhury S, Basu A, Kundu S. Overexpression of a new osmotin-like protein gene (SindOLP) confers tolerance against biotic and abiotic stresses in sesame. Frontiers in Plant Science, 2017; 8:410.

23. Hammond-Kosack KE, Jones J. Resistance genedependent plant defense responses. The Plant Cell, 1996; 8 (10): 1773

24. Showalter AM. Structure and function of plant cell wall proteins. The Plant Cell, 1993; 5 (1): 9.

25. Duplan V, Rivas S. E3 ubiquitin-ligases and their target proteins during the regulation of plant innate immunity. Frontiers in Plant Science, 2014; 5:42.

26. Wang YS, Pi LY, Chen X, Chakrabarty PK, Jiang J, De Leon $A L$, et al. Rice $X A 21$ binding protein 3 is a ubiquitin ligase required for full $\mathrm{Xa21-mediated}$ disease resistance. The Plant Cell, 2006; 18 (12):3635-3646.

27. Vartapetian AB, Tuzhikov Al, Chichkova NV, Taliansky M, Wolpert TJ. A plant alternative to animal caspases: subtilisin-like proteases. Cell Death Differ. 2011; 18:1289-1297

28. Higashi $K$, Ishiga $Y$, Inagaki $Y$, Toyoda K, Shiraishi $T$, Ichinose Y. Modulation of defense signal transduction by flagellin-induced WRKY41 transcription factor in Arabidopsis thaliana.
Molecular Genetics and Genomics, 2008; 279 (3): 303-312.

29. Nadarajah, K., Omar NS, and Tan YT. Molecular characterization of a WRKY gene from Oryza sativa indica cultivar UKMRC9. Plant Omics Journal 2014; 7 (2): 63-71.

30. Ambawat S, Sharma P, Yadav NR, Yadav RC. MYB transcription factor genes as regulators for plant responses: an overview. Physiology and Molecular Biology of Plants. 2013; 19 (3): 307-21.

31. Zhang S, Yang X, Sun M, Sun F, Deng S, Dong H. Riboflavin induced priming for pathogen defense in Arabidopsis thaliana. Journal of Integrative Plant Biology 2009; 51(2): 167-74.

32. Chanthran SSD, Cheah BH, Nadarajah K. In silico analysis of disease resistance and defence related genes for a major sheath blight qShb 9-2 QTL in rice. Malaysian Journal of Microbiology 2018; 14(6): 534-546.

33. Kumar IS, Cheah BH, Nadarajah K. In silico identification and classification of disease resistance genes and defense-related genes against sheath blight from QTL qSBR11-1 in rice (Oryza sativa L.). Undergrad Research Journal of Integrative Biology, 2017; 1.

34. Kumar IS, Amran NA, Nadarajah K. In silico analysis of qBFR4 and qLBL5 in Conferring Quantitative Resistance Against Rice Blast. J Pure Appl Microbiol. 2018; 12(4) (In Press)

35. Kumar A, Sandhu N, Dixit S, Yadav S, Swamy B, Shamsudin NAA. Marker-assisted selection strategy to pyramid two or more QTLs for quantitative trait-grain yield under drought. Rice 2018; 11(1), 35. 